\title{
Effect of selected organic acids on degumming and properties of tassar silk
}

\author{
ANURADHA SINGH AND SUMAN PANT
}

Received: 22.05.2014; Revised: 05.10.2014; Accepted: 18.10.2014

See end of the paper for authors' affiliations ANURADHA SINGH

Department of Home Science, Banasthali University, BANASTHALI (RAJASTHAN) INDIA Email:anuradhasingh.singh604@ gmail.com
ABSTRACT : Present study was conducted to find out the effect of organic acid on the degumming of oak tassar silk fabric. Degumming of tassar silk fabric was done with tartaric acid, oxalic acid and citric acid at different $\mathrm{pH}$, and for different duration to find out most appropriate conditions for degumming. Selected physical properties of oak tassar silk fabric was evaluated. Tartaric acid was found to give the best result followed by oxalic acid and citric acid for degumming silk. Weight, thickness, per cent drape coefficient and strength of tassar silk fabric increased whereas stiffness of fabric decreased.

KEY WORDS: Degumming, Oak tassar, Stiffness, Drapability, Strength

- HOW TO CITE THIS PAPER : Singh, Anuradha and Pant, Suman (2014). Effect of selected organic acids on degumming and properties of tassar silk. Asian J. Home Sci., 9 (2) : 470-472. 